\title{
CHANGES IN THE MIDDLE AND UPPER ATMOSPHERE PARAMETERS DURING THE JANUARY 2013 SUDDEN STRATOSPHERIC WARMING
}

\author{
A.S. Yasyukevich \\ Institute of Solar-Terrestrial Physics SB RAS, \\ Irkutsk, Russia,annpol@iszf.irk.ru
}

\section{M.V. Klimenko}

Kaliningrad Branch of N.V. Pushkov Institute of Terrestrial Magnetism, Ionosphere and Radio Wave Propagation RAS, Kaliningrad,Russia, maksim.klimenko@mail.ru

Immanuel Kant Baltic Federal University,

Kaliningrad,Russia,maksim.klimenko@mail.ru

\section{Yu.Yu. Kulikov}

Institute of Applied Physics RAS,

Nizhny Novgorod, Russia, yuyukul@appl.sci-nnov.ru

\section{V.V. Klimenko}

Kaliningrad Branch of N.V. Pushkov Institute of Terrestrial Magnetism, Ionosphere and Radio Wave Propagation RAS, Kaliningrad,Russia,vvk_48@mail.ru

\section{F.S. Bessarab}

Kaliningrad Branch of N.V. Pushkov Institute of Terrestrial Magnetism, Ionosphere and Radio Wave Propagation RAS, Kaliningrad, Russia, bessarabf@gmail.com

Immanuel Kant Baltic Federal University,

Kaliningrad, Russia, bessarabf@gmail.com

\section{Yu.N. Korenkov}

Kaliningrad Branch of N.V. Pushkov Institute of Terrestrial Magnetism, Ionosphere and Radio Wave Propagation RAS, Kaliningrad,Russia,office@wdizmiran.ru

V.N. Marichev

V.E. Zuev Institute of Atmospheric Optics SB RAS,

Tomsk,Russia,marichev@iao.ru

\section{K.G. Ratovsky}

Institute of Solar-Terrestrial Physics SB RAS,

Irkutsk, Russia,ratovsky@iszf.irk.ru

\author{
S.A. Kolesnik \\ Tomsk State University, \\ Tomsk,Russia,serkol@mail.tsu.ru
}

\begin{abstract}
We present the results of complex observations of various parameters of the middle and upper atmosphere over Siberia in December 2012 - January 2013, during a major sudden stratospheric warming (SSW) event. We analyze variations in ozone concentration from microwave measurements, in stratosphere and lower mesosphere temperatures from lidar and satellite measurements, in the F2-layer critical frequency $\left(f_{\mathrm{o}} \mathrm{F} 2\right)$, in the total electron content (TEC), as well as in the ratio of concentrations of atomic oxygen to molecular nitrogen $\left(\mathrm{O} / \mathrm{N}_{2}\right)$ in the thermosphere. To interpret the observed disturbances in the upper atmosphere, the experimental measurements are compared with the results of model calculations obtained with the Global Self-
\end{abstract}

Consistent Model of Thermosphere-IonosphereProtonosphere (GSM TIP). The response of the upper atmosphere to the SSW event is shown to be a decrease in $f_{\mathrm{o}} \mathrm{F} 2$ and TEC during the evolution of the warming event and a prolonged increase in $\mathrm{O} / \mathrm{N}_{2}, f_{0} \mathrm{~F} 2$, and TEC after the SSW maximum. For the first time, we observe the relation between the increase in stratospheric ozone, thermospheric $\mathrm{O} / \mathrm{N}_{2}$, and ionospheric electron density for a fairly long time (up to 20 days) after the SSW maximum at midlatitudes.

Keywords: sudden stratospheric warming, ozone, stratosphere, ionosphere, electron density, total electron content, atmosphere-ionosphere coupling.

\section{INTRODUCTION}

The December 2012 - January 2013 period is of particular interest for the study of solar-terrestrial physics and atmosphere-ionosphere coupling because it exhibits an almost simultaneous significant increase in solar activity and a sudden stratospheric warming (SSW). By SSW is meant an explosive increase in the temperature of the high-latitude stratosphere in winter months. Being quiet, the winter polar stratosphere features a stable large-scale circumpolar vortex centered near the Pole. Air masses in the vortex move at a high speed (up to $100 \mathrm{~m} / \mathrm{s}$ ) from west to east, forming the so-called jet stream, with low temperature in the stratosphere $(200 \mathrm{~K}$ and lower). According to the classical scenario, the evolution of SSW is associated with the intensification of orographic stationary planetary waves (SPW) in the troposphere [Matsuno, 1971]. In winter, SPW can pene- trate into higher atmospheric layers, interacting with the eastward stratospheric stream. Such interaction results in a weakening or disruption of the circumpolar vortex in the high-latitude stratosphere; there also may be a shift of the vortex from the Pole [Charlton, Polvani, 2007]. Upward SPW transfer heat toward the Pole, thus causing an increase in the temperature of the highlatitude (polar) stratosphere [Matsuno, 1971]. As a result, during SSW events the stratospheric temperature may rise by more than $50 \mathrm{~K}$ for a few days or even weeks relative to quiet conditions. In recent years, it has been shown that the enhancement of the nonlinear interaction between SPW and mean flow, which results in an increase in the intensity of irregular oscillations - the so-called stratospheric vacillations - may also be one of the causes of SSW [Pogoreltsev et al. 2014]. The warming events during which, along with the polar tempera- 
ture rise, the mean zonal circulation and temperature gradient over the hemisphere change their directions are assigned to major SSW; and the day when at a $10 \mathrm{hPa}$ level and $60^{\circ}$ latitude the zonal circulation changes its direction is called maximum of SSW [Schoeberl, 1978]. The stratosphere returns to normal conditions (recovery phase) after the SSW maximum, and usually more slowly than the SSW event develops.

In the winter stratosphere/lower mesosphere during SSW events, the polar vortex structure is radically transformed [Labitzke, 1972; Schoeberl, 1978]. This has a significant effect on the distribution of meteorological parameters both in the troposphere and in the lowest atmospheric layer, and, as a consequence, on the weather [Sun, Robinson, 2009]. Shpynev et al. [2015a] and Yasyukevich et al. [2017] have shown that the transformation of the polar vortex structure during SSW is also accompanied by an increase in the intensity of medium scale wave disturbances in the middle atmosphere.

It has been found that during SSW events significant changes occur in the stratospheric ozone concentration at different heights [Kulikov et al., 2002; Scheiben et al., 2012; Manney et al., 2015]. While the concentration of this gas in the atmosphere is low, the ozone layer is of crucial importance for global survival, and variations in its density have a marked effect on climate [Baldwin et al., 2007]. Temperature variations in the stratosphere during SSW affect the coefficients of ozone formation and destruction. The ozone concentration is also influenced by the processes associated with the polar vortex breakdown [Tao et al., 2015], the formation of polar stratospheric clouds [Smyshlyaev et al., 2016], and the activation of chemical losses of the stratospheric ozone [Manney et al., 2015]. Hocke et al. [2015] have carried out a composite analysis of the total ozone content (TOC) at heights 5-60 km and a latitude of $80^{\circ}$ during $20 \mathrm{SSW}$ and have established that after SSW maxima TOC far exceeds climate values (up to 90 Dobson Units, DU). On the contrary, a negative anomaly in the polar ozone content $(\sim-20$ DU) is present for up to 90 days before SSW. Similar ozone variations at $10 \mathrm{hPa}$ over Moscow were recorded through microwave measurements during the 2012/2013 winter SSW [Solomonov et al., 2017].

SSW events have an effect of higher atmospheric layers: mesosphere, thermosphere, and ionosphere. In the mesosphere above the warming zone in the stratosphere, the temperature decreases [Labitzke, 1981]. So, during the 2008/2009 major winter SSW, Lukianova et al. [2015] at the Sodankylä station observed a pronounced cooling of the mesosphere, comparable in magnitude with the temperature change in the stratosphere $(\sim 50 \mathrm{~K})$. Medvedeva et al. [2015] also recorded a change in the mesosphere/lower thermosphere (MLT) temperature during the 2012/2013 SSW event and an increase in $\mathrm{OH}$ $(\sim 87 \mathrm{~km})$ and $\mathrm{O}_{2}(\sim 94 \mathrm{~km})$ emission intensities $2-2.5$ times compared to undisturbed conditions. A threefourfold increase in the oxygen emission intensity in the mesosphere during SSW was also reported in [Shepherd et al., 2010; Shepherd, Shepherd, 2011].

In the thermosphere at heights above $140 \mathrm{~km}$, variations in the atomic oxygen emission intensity have a different nature: during the 1993 SSW maximum phase, the oxygen emission significantly decreased, whereas during the recovery phase the emission intensity exceeded the values recorded before the warming [Shepherd, Shepherd, 2011]. During four SSW in 2010-2013, Laskar, Pallamraju [2014] recorded a systematic increase in the daytime oxygen emission at low latitudes, accompanied by a simultaneous increase in the temperature of the polar thermosphere and by an enhancement of the equatorward heat transfer. From the observational results the authors suggested that during SSW at MLT heights a secondary meridional circulation cell is formed which promotes the oxygen outflow from the high-latitude thermosphere and its transport to the equatorial thermosphere. An increase in the mid-latitude thermospheric temperature during SSW was also detected with the Millstone Hill radar [Goncharenko, Zhang, 2008].

Corresponding variations in the temperature of the mesosphere and lower thermosphere during SSW as well as a decrease in the maximum density and velocity of the atomic oxygen emission at high latitudes were derived from model calculations [Liu, Roble, 2002]. Thus, the experimental and model results demonstrate global changes in the dynamics and composition of the neutral atmosphere at all heights from the stratosphere to the thermosphere during SSW events.

An increase in wave activity and significant changes in the atmospheric circulation during SSW also have an effect on ionospheric plasma, with the ionospheric response to SSW events varying at different latitudes. The response of the equatorial ionosphere to SSW has a semidiurnal structure involving a significant electron density increase relative to quiet days during prenoon hours with its subsequent fall in the afternoon [Chau et al., 2010, 2012; Goncharenko et al., 2010a, b; Yue et al., 2010]. This effect is associated primarily with variations in the equatorial vertical electromagnetic plasma drift [Chau et al., 2009, Goncharenko et al., 2010a; Klimenko et al., 2015], caused by variations in the neutral atmospheric circulation (predominately of the zonal wind) resulting from the modification of atmospheric tides [Chau et al., 2010, Fuller-Rowell et al., 2010; Pedatella et al., 2014].

In the mid-latitude and polar ionosphere during SSW maxima, there was a largely negative response in the electron density [Pancheva, Mukhtarov, 2011; Bessarab et al., 2012; Polyakova et al., 2014; Yasyukevich, 2018]. In contrast, during the recovery phase (up to 20 days), the ionospheric electron density far exceeded monthly averages [Polyakova et al., 2014; Yasyukevich, 2018]. A cause of the negative/positive electron density disturbances during SSW development and in the recovery phase is likely to be $\mathrm{SSW}$ associated $\mathrm{O} / \mathrm{N}_{2}$ variations in the thermosphere [Korenkov et al., 2012; Klimenko et al., 2013; Shpynev et al., 2015b; Yasyukevich, 2018].

In this paper, we report the results of comprehensive observations of various parameters of the middle and upper atmosphere over Eastern Siberia in January 2013 during a major SSW, which is one of the longest events of this type on record [Goncharenko et al., 2013]. To interpret variations in the upper atmosphere parameters, we have used the results of numerical model calculations. 


\section{DATA AND RESEARCH METHOD}

The study of stratospheric changes is based on the complex experiment (lidar and microwave observations), carried out in Tomsk in January 2013 [Marichev et al., 2014; Matvienko et al., 2016].

The method of ground-based microwave radiometry involves measuring the rotational spectra of trace gas (in our case, ozone) emission in millimeter and submillimeter wave ranges. The accuracy of the observations by microwave methods depends weakly on weather conditions and the presence of aerosols in the atmosphere, which is an advantage as compared to optical and infrared observations. Furthermore, microwave ozone observations can be made 24 hours a day. Recently, there has been a significant advance in the development of newgeneration mobile microwave spectrometers [Kulikov et al., 2007]. The use of mobile ozonemeters allowed us to accomplish a number of tasks under severe field conditions, which would be difficult to perform using the standard microwave technique. Information about the $\mathrm{O}_{3}$ content is in the measured spectrum of integral atmospheric radiation in the vicinity of the rotational spectral line of this gas. With the spectrum inversion we can obtain data on the vertical ozone distribution (VOD) in the atmosphere. When solving the problem of estimating the vertical ozone profile, we used model height dependences of pressure and temperature. The error in determining VOD from its spectra does not exceed 20 $\%$. The use of the real temperature distribution to estimate the ozone profile decreases the error in determining VOD to $10 \%$ in the height range $20-40 \mathrm{~km}$.

The device consists of a heterodyne uncooled receiver tuned to a fixed frequency of $110836.04 \mathrm{MHz}$ corresponding to the rotational transition of the ozone molecule $6_{0.6}-6_{1.5}$, and a multichannel spectrum analyzer. At the receiver input is a module comprising an antenna (scalar horn) and a commutator for calibrating the level of the received thermal radiation of the atmosphere. The beam width of the horn antenna at $3 \mathrm{~dB}$ is $5.4^{\circ}$. The single sideband noise temperature of the receiver is $2500 \mathrm{~K}$. The receiving mode in one bandwidth is provided by a low-cutoff filter (waveguide) with direct losses of $0.5 \mathrm{~dB}$ and mirror channel suppression of more than $20 \mathrm{~dB}$. The spectrum analyzer includes 31 filters with a bandwidth of 1 to $10 \mathrm{MHz}$ and a total frequency band of $240 \mathrm{MHz}$. The device parameters allow us to measure the ozone radiation spectrum accurate to $\sim 2 \%$. Spectra of atmospheric thermal radiation are measured using a method of calibration by two "blackbody" standards, which are at the liquid nitrogen boiling temperature and at the ambient air temperature.

Ground-based lidar measurements of thermal conditions of the stratosphere and mesosphere over Tomsk were initiated at the V.E. Zuev Institute of Atmospheric Optics of Siberian Branch of the Russian Academy of Sciences in 1994 [Matvienko et al., 2009]. The lidar measurements of the vertical temperature distribution from molecular (or Rayleigh) light scattering are based on an unambiguous relationship between the molecular backscatter coefficient and the atmospheric density at a certain height. The lidar complex includes an Nd:YAG transmitter - a laser with a collimator, with a wavelength of $532 \mathrm{~nm}$, pulse energy up to $200 \mathrm{~mJ}$, pulse train rate of $10 \mathrm{~Hz}$, output beam spread of $0.1 \mathrm{mrad}$; receiving and recording system - a Newton telescope with the primary mirror diameter of $1 \mathrm{~m}$ and focal length of $2 \mathrm{~m}$. The ionospheric sounding is performed at night. Backscatter signals are received in the photon-counting mode. The photodetector is connected to a computer, which controls measurements as well as data acquisition and processing. The resulting vertical resolution for the temperature profile is $192 \mathrm{~m}$, and the accumulation time necessary to obtain information about temperature from a height of $60 \mathrm{~km}$ is $\sim 2 \mathrm{hrs}$. This time is determined by a relative error of $10 \%$ at a maximum height. The relative error of measurements depends on the number of photons received from a given height, which is determined by the duration of the strobe, the number of laser shots, aerosol and air densities, and background light. In this case, at $30-40 \mathrm{~km}$ the relative error is $2 \%$, i.e. it does not exceed $\sim 2.5 \mathrm{~K}$ at $40 \mathrm{~km}$.

Variations in parameters of the stratosphere and lower mesosphere (temperature, wind) were also estimated from ERA-Interim data [http://www.esrl.noaa.gov; Dee et al., 2011]. These data are global fields of basic parameters of the neutral atmosphere (temperature, wind, geopotential, etc.) at standard levels of up to $1 \mathrm{hPa}(46-48 \mathrm{~km})$. The data on planetary wave activity in the period of interest were obtained from the MERRA reanalysis dataset [https://gmao.gsfc.nasa.gov/reana-lysis/MERRA].

Results of the complex experiment were complemented by observations of ionospheric parameters for this period. The paper examines variations in the F2layer critical frequency $\left(f_{\mathrm{o}} \mathrm{F} 2\right)$ from ionosonde measurements at Tomsk $\left(85^{\circ} \mathrm{E}, 56^{\circ} \mathrm{N}\right)$ and Irkutsk $\left(104^{\circ} \mathrm{E}\right.$, $\left.52^{\circ} \mathrm{N}\right)$. Besides, we analyze the behavior of the total electron content (TEC), using data from GPS/GLONASS dual-frequency phase receivers of the IGS network [Dow et al., 2009] located in the nearest points. Vertical TEC series $I_{\mathrm{v}}$ were derived from initial slant TEC data by the method described in [Yasyukevich et al., 2015]. Time resolution of $f_{\mathrm{o}} \mathrm{F} 2$ and vertical TEC data is $15 \mathrm{~min}$. For each day, we calculate daily average $f_{\mathrm{o}} \mathrm{F} 2$ and TEC for the time interval 10-16 LT.

The $\mathrm{O} / \mathrm{N}_{2}$ variations in the thermosphere are analyzed from measurements of the Global Ultra-Violet Imager (GUVI) onboard the TIMED (Thermosphere, Ionosphere, Mesosphere Energetics and Dynamics) satellite [Strickland et al., 2004]. The calculation of the column integrated $\mathrm{O} / \mathrm{N}_{2}$ ratio involves measuring the dayglow intensity of atomic oxygen $(\mathrm{O})$ at the $135.6 \mathrm{~nm}$ wavelength and nitrogen $\left(\mathrm{N}_{2}\right.$, Lyman - Birge - Hop) in the far ultraviolet. As a result, the GUVI data represent the ratio of integral densities $\mathrm{O} / \mathrm{N}_{2}$ in the daytime, computed from the height at which the $\mathrm{N}_{2}$ integral is $10^{17}$ $\mathrm{cm}^{-2}$ (about $140 \mathrm{~km}$ ) [Christensen et al., 2003].

To interpret disturbances in the upper atmosphere, experimental measurements were compared with the model calculations from the Global Self-Consistent Model of the Thermosphere, Ionosphere and Protonosphere (GSM TIP) [Namgaladze et al,. 1988; Korenkov 
et al., 1998]. The model is based on the numerical integration of the system of quasi-hydrodynamic equations of continuity, motion, and heat balance for neutral and charged particles of thermal near-Earth plasma together with the equation for electric field potential in the height range from $80 \mathrm{~km}$ to the geocentric distance of 15 Earth radii in terms of the mismatch between geographic and geomagnetic axes. For given input parameters, GSM TIP calculates global distributions of temperature $T_{\mathrm{n}}$, densities of $\mathrm{O}_{2}, \mathrm{~N}_{2}, \mathrm{O}$, and vector of the mean mass velocity of the neutral component of Earth's upper atmosphere, densities, temperature, and velocities of atomic $\left(\mathrm{O}^{+}, \mathrm{H}^{+}\right)$and molecular ions and electrons, as well as the two-dimensional distribution of the potential of ionospheric and magnetospheric electric fields. The geomagnetic field is approximated by the central dipole. The model uses a spatial grid in the geomagnetic coordinate system with a step of $5^{\circ}$ in latitude, $5^{\circ}$ in longitude, and a variable vertical step increasing with height.

GSM TIP was utilized for two calculations of ionospheric parameters for the period from December 22, 2012 to January 25, 2013:

1) without regard to day-to-day solar activity variations (the calculation results show only climatological seasonal variations);

2) with regard to solar activity variations.

In both the variants, the SSW effect is disregarded, and we associate the ionospheric effects ignored in the model with SSW. Note that this approach is not without some drawbacks. For example, it ignores possible changes in the lower atmosphere due to an increase in solar activity. However, we believe that these effects are much weaker than the SSW effect, caused by significant temperature variations and wave activity increase. To interpret ionospheric disturbances during the period of interest more correctly, it is necessary to use a model describing the behavior of the parameters of the lower and upper atmosphere such as the EAGLE model [Klimenko et al., 2018a]. In future, we plan to conduct such a study.

\section{VARIATIONS IN THE STRATOSPHERE AND LOWER MESOSPHERE DURING SSW}

The stratospheric warming in December 2012 January 2013 is classified as major. Figure 1 shows distributions of zonal mean values of temperature $(a)$ and zonal wind speed $(b)$ at a latitude of $60^{\circ} \mathrm{N}$ in the middle (10 hPa, black lines) and upper stratosphere/lower mesosphere ( $1 \mathrm{hPa}$, gray curves) as derived from ERA-Interim data versus values averaged over 10 years (dashed lines). Figure 1, $c$ displays variations in amplitude of SPW with zonal wavenumber 1 (gray curve) and 2 (black curve) for a geopotential height at the $10 \mathrm{hPa}$ level and $60^{\circ} \mathrm{N}$ latitude according to MERRA reanalysis data.

As noted above, the development of SSW is due to the intensification of planetary waves. It can be seen that the increase in the planetary wave amplitude with zonal
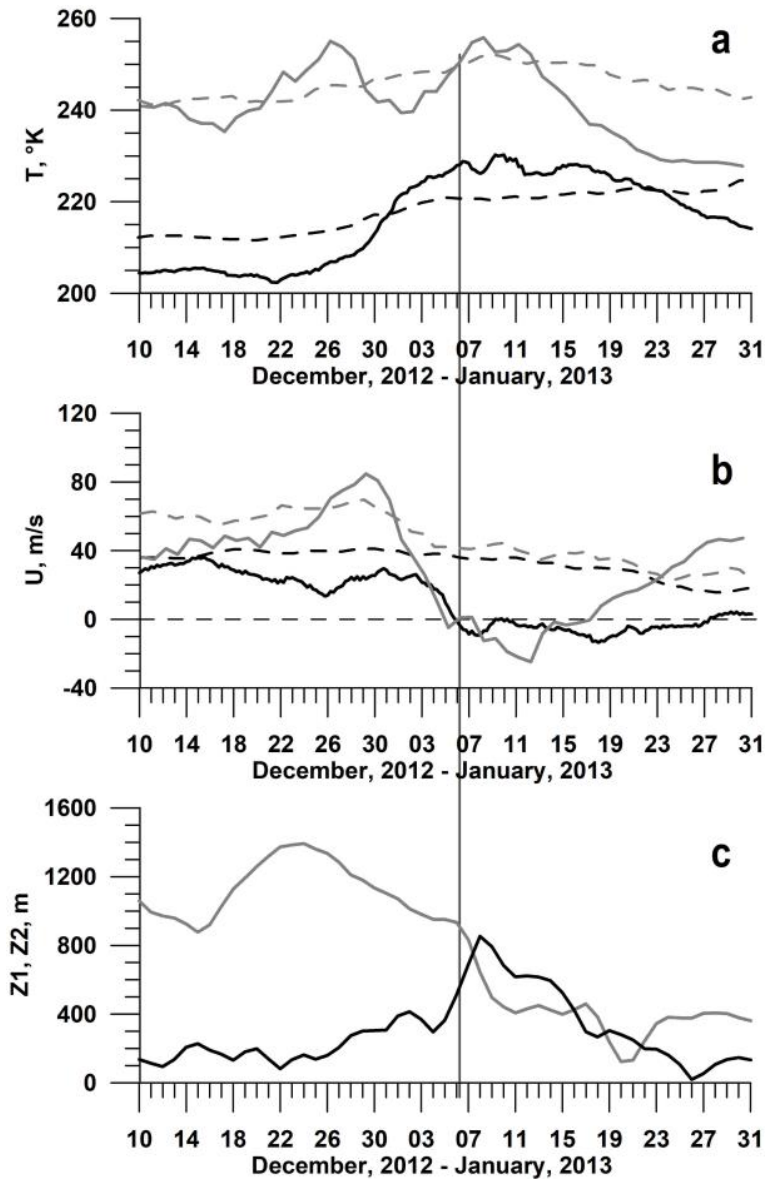

Figure 1. Variations in $60^{\circ} \mathrm{N}$ latitude zonal mean values of: temperature $(a)$, zonal wind speed $(b)$ in the middle $(10$ $\mathrm{hPa}$, black curves) and upper stratosphere/lower mesosphere (1 $\mathrm{hPa}$, gray curves) versus 10-year averaged values (dashed lines); variations in amplitude of SPW 1 (gray curve) and 2 (black curve) for a geopotential height at the $10 \mathrm{hPa}$ level and a latitude of $60^{\circ} \mathrm{N}(c)$

number 1 (SPW1) began on December 14, 2012; and on December 22 for SPW1 the amplitude was maximum. Then SPW with zonal number 2 (SPW2) increased until January 8 . The increase in the SPW1 intensity manifested itself in the polar vortex shift relative to the Pole, whereas the intensification of SPW2 was accompanied by polar vortex splitting.

The zonal mean stratospheric temperature $(10 \mathrm{hPa}, \sim$ $30 \mathrm{~km}$ ) at a latitude of $60^{\circ} \mathrm{N}$ began to increase on December 21, 2012 (Figure 1,a). A decrease in the zonal mean zonal wind speed in the stratosphere was detected later - at the end of December (Figure 1, b). The wind changed direction from eastward to westward at $10 \mathrm{hPa}$ on January 6 - the day when SSW reached maximum. The recovery of the stratospheric circulation to the normal conditions continued throughout the month; the zonal mean zonal wind became eastward only at the end of January (Figure 1, b).

Figure 2 shows spatial distributions of stratospheric temperature at $10 \mathrm{hPa}$ on some days of the period of interest in the polar coordinate system.

Bold curves are isolines of the geopotential height; symbols mark points at which the experiment was carried out (Tomsk, Irkutsk). 
TEMPERATURE 22/12/2012/12 UT $10 \mathrm{gPa}$

a

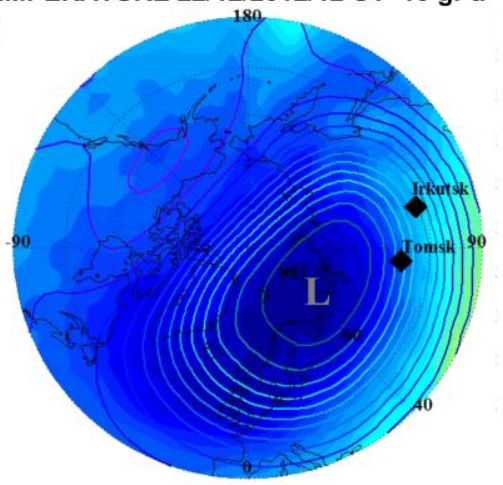

TEMPERATURE 06/01/2013/12 UT $10 \mathrm{gPa}$ d

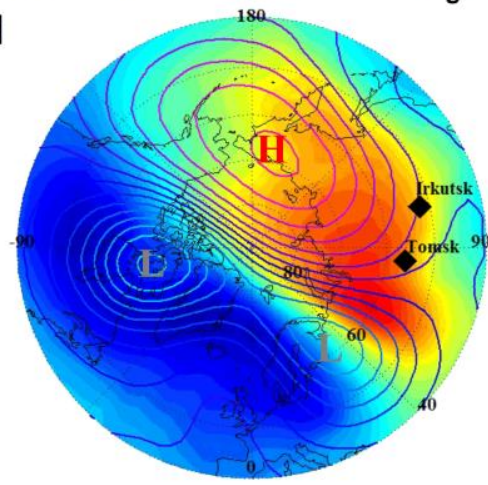

TEMPERATURE 29/12/2012/12 UT $10 \mathrm{gPa}$ b
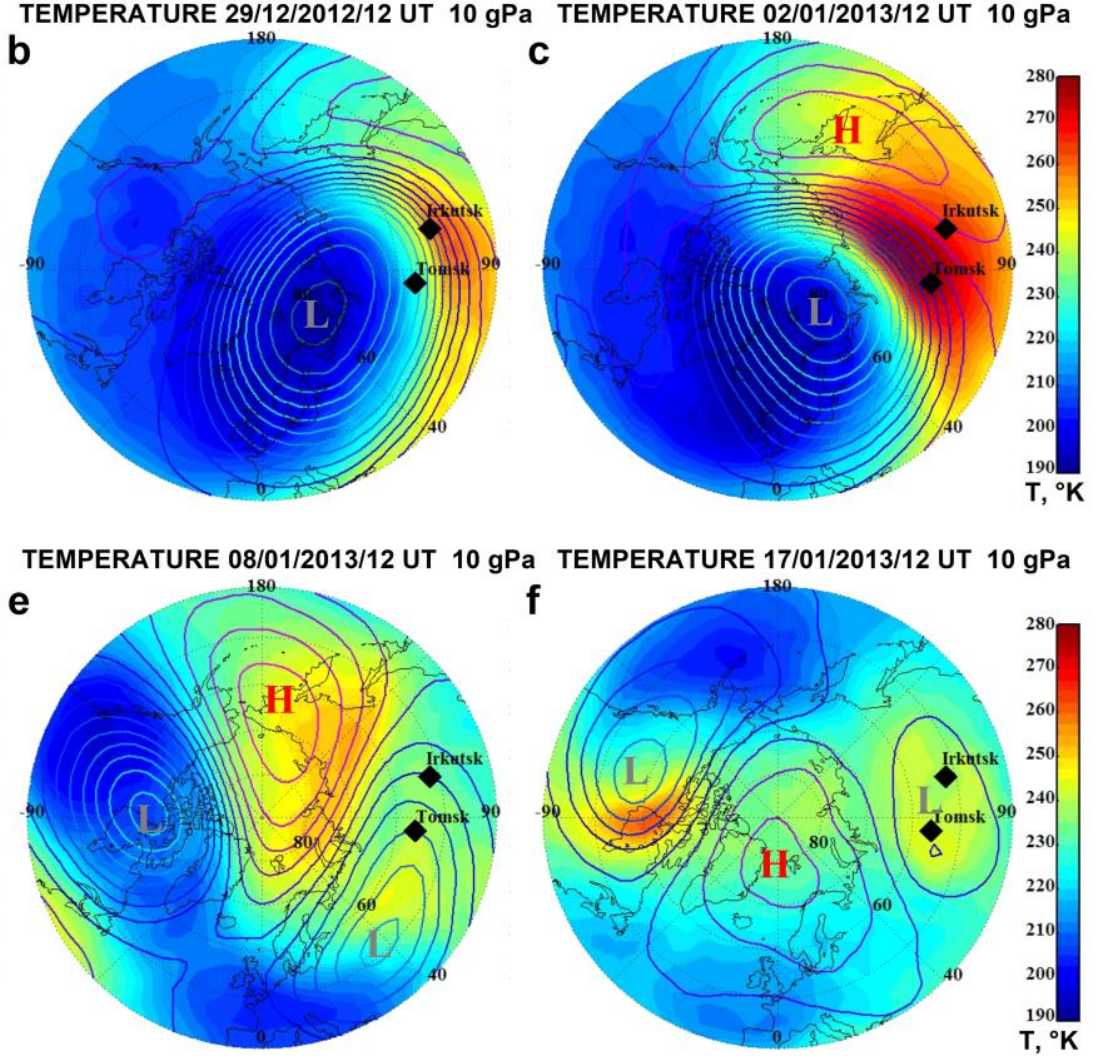

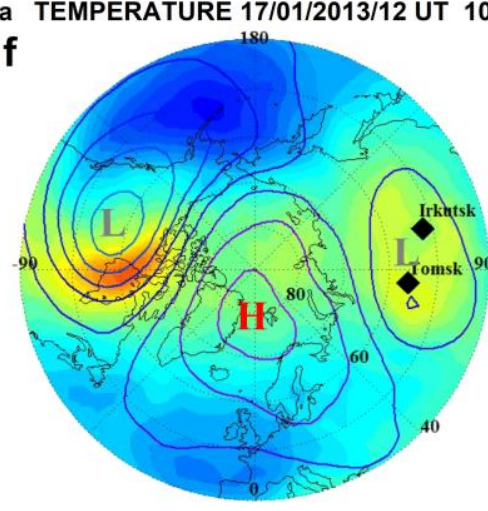

$\mathrm{gPa}$

Figure 2. Maps of the stratospheric temperature $(10 \mathrm{hPa})$ at $12 \mathrm{UT}$ for some days from December 22, 2012 to January 17, 2013. Bold curves are isolines of the geopotential height. Diamonds mark locations of Irkutsk and Tomsk

It is seen that during the development and maximum of SSW the region of the greatest increase in the stratospheric temperature is in North Asia, and the temperature near the points considered increases by more than $50 \mathrm{~K}$ (Figure 2, c, d). We clearly observe the formation of a stratospheric anticyclone $(\mathrm{H})$ and its movement from midlatitudes to the Pole. After January 6, the polar cyclone split into two low-pressure cells (L), which shifted to middle latitudes in the Asian and North American regions. The stratospheric temperature remained elevated throughout January, but in the second half of the month the highest temperature region occurred in the North Atlantic region (Figure 2, $f$ ).

Figure 3 illustrates horizontal wind fields at $10 \mathrm{hPa}$ as derived from ERA-Interim data. The color scale demonstrates the modulus of the wind speed, and arrows indicate its direction. We can see significant changes in the stratospheric circulation during the period of interest. In the stratosphere on December 22 there was a well-developed intense jet stream associated with the polar cyclone, and the circulation was mainly zonal (geostrophic). In this case, the vortex center was shifted markedly from the Pole. As the SSW event developed from the end of December to the beginning of January, there was a further shift of the jet stream from the Pole followed by its transformation and splitting on January 6 , the day of the SSW maximum (Figure 3,d). From the end of December, we observe the formation of an anticyclonic circulation cell (Figure $3, b$ ) atypical of the winter polar stratosphere during quiet periods. The anti- cyclonic cell was observed to the end of January, with the wind speed modulus across the polar stratosphere being low as compared to those typical for winter. Note that Tomsk and Irkutsk in late December - early January were in the polar vortex zone (Figure 3,a-c), and from middle January, in the cyclonic circulation cell produced by the vortex splitting (Figure 3,e,f).

Significant changes in the stratospheric circulation have a pronounced effect on the distribution of the neutral atmosphere components (particularly, ozone) because they promote mixing of air masses from different latitudes. Besides, Shpynev et al. [2015a] have shown that such transformations of jet streams lead to the excitation of wave disturbances with periods of internal gravity waves at stratomesospheric heights.

\section{OZONE VARIATIONS}

Figure 4 presents microwave measurements of ozone concentration in Tomsk at heights of 25 and $40 \mathrm{~km}$ in comparison with the behavior of the ozone volume mixing ratio as derived from ERA-Interim data. Also shown are stratospheric temperature variations at these heights derived from lidar measurements and MLS Aura data [https://disc.gsfc.nasa.gov/datasets]. There is good agreement in the dynamics of parameters obtained from the ground-based experiment and independent data. The greatest discrepancy for the stratospheric temperature occurs at $40 \mathrm{~km}$, but at the same height the lidar measurement error increases. Note a significant growth in the temperature of the lower stratosphere that began 
WIND FIELD 22/12/2012/12 UT $10 \mathrm{gPa}$

a

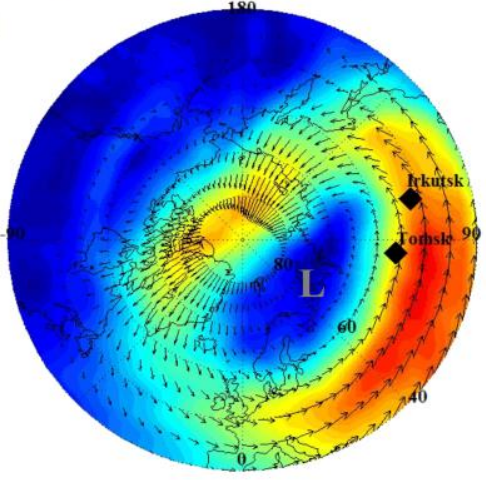

WIND FIELD 06/01/2013/12 UT $10 \mathrm{gPa}$

d

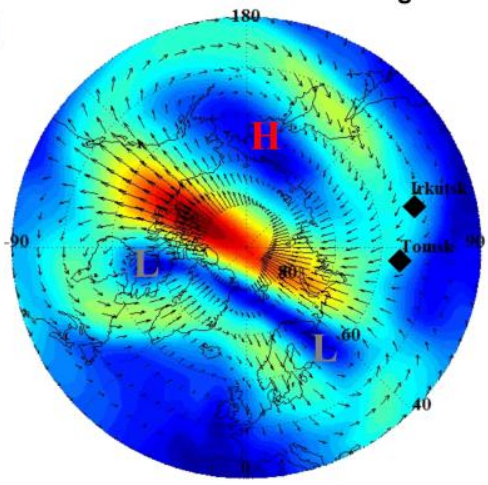

b

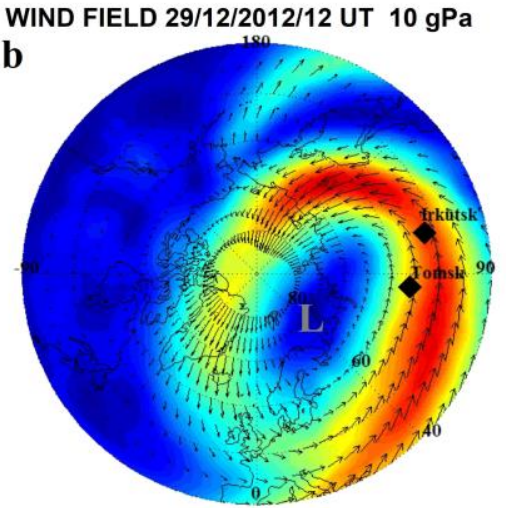

WIND FIELD 08/01/2013/12 UT $10 \mathrm{gPa}$

e

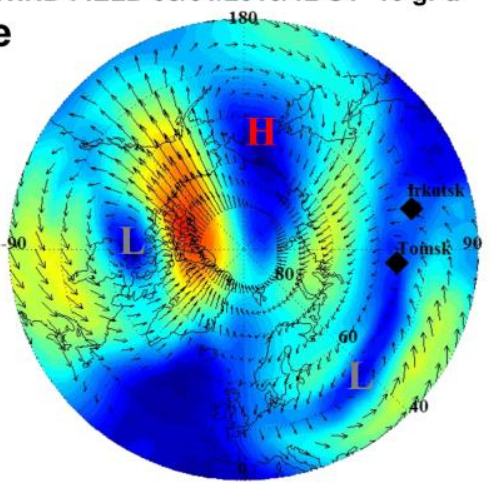

WIND FIELD 02/01/2013/12 UT $10 \mathrm{gPa}$

C

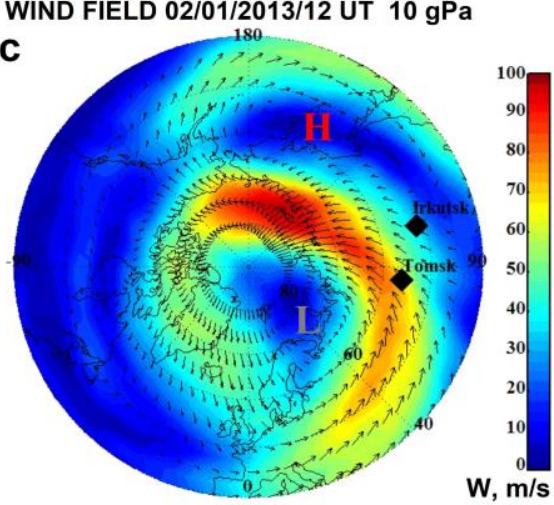

WIND FIELD 17/01/2013/12 UT $10 \mathrm{gPa}$

f

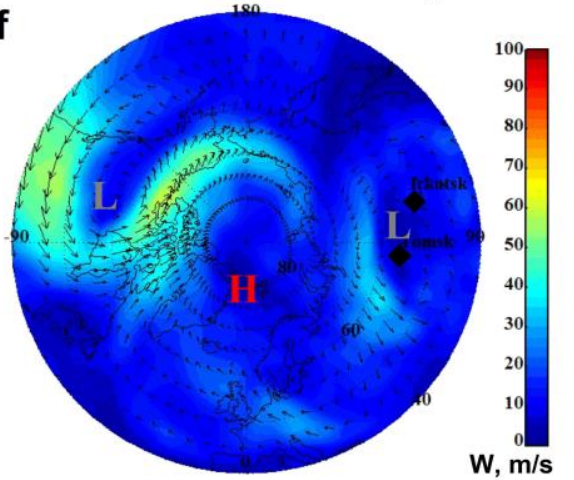

Figure 3. Horizontal wind fields in the stratosphere at $10 \mathrm{hPa}$. The color scale demonstrates the wind speed modulus; arrows show the wind direction

on December 20 (Figure 4,c). A peak temperature over Tomsk was recorded on January 5, and a total temperature rise was $\sim 60 \mathrm{~K}$. In the higher stratospheric layers, the temperature increase began earlier, and in late December it was followed by a sharp cooling by $\sim 40 \mathrm{~K}$ (Figure $4, d$ ) with a minimum temperature on January 11 . This corresponds to the typical behavior of the temperature in the stratosphere/lower mesosphere during SSW.

In the given period, there were also considerable ozone variations. At $25 \mathrm{~km}$ from middle December there was a significant ozone decrease by up to $50 \%$. A feature of this period is also the lack of correlation between atmospheric temperature and ozone concentration. This suggests that dynamic processes have a predominant influence on ozone at these heights. Manney et al. [2015] have shown that during this SSW event the combination of dynamic and meteorological conditions led to an unprecedented intensification of chemical ozone losses in the middle stratosphere in areas located inside cyclonic cells. The observed ozone decrease in the lower stratosphere (Figure 4,a) can also be caused by the inflow of ozone-poor air masses into the analyzed region from low latitudes of the Atlantic (Figure 3, $d, e$ ) [Marichev et al., 2014]. The ozone concentration began to increase after January 14, i.e. a week after the SSW maximum; the increase was likely to be due to the weakening of the cyclonic cell over Siberia and the increase in geopotential (Figure 2, 3, $f$ ) [Solomonov et al., 2017].

Note that for January 8-18 the ozone observations and ERA-Interim data at $25 \mathrm{~km}$ differ significantly
(Figure 4, a). This discrepancy can probably be explained by the fact that the ozone concentrations from the archive are the result of postprocessing of available measurements with different kinds of assimilation and interpolation models, which are not free from some shortcomings [Dee at al., 2011]. On the other hand, the error of measurements with the equipment we use does not exceed $20 \%$. In this regard, we believe that more reliable ozone concentrations in this case are those derived from the experiment.

At higher stratospheric layers, the ozone concentration is largely determined by photochemical processes [Marichev et al., 2014], and ozone concentration variations are in antiphase with temperature variations (Figure $4, b, d$ ). It is evident that from late December to middle January during SSW the ozone concentration at $40 \mathrm{~km}$ increased approximately twofold.

\section{VARIATIONS IN THERMOSPHERIC AND IONOSPHERIC PARAMETERS}

Figure 5 displays the variations in midday $f_{\mathrm{o}} \mathrm{F} 2$, $\mathrm{TEC}$, and $\mathrm{O} / \mathrm{N}_{2}$ derived from experimental data and the results of model calculations.

Also shown are variations in the solar radio flux at a wavelength of $10.7 \mathrm{~cm}(F 10.7)$ and in the geomagnetic index $K_{\mathrm{p}}$.

The results of the model calculations are given with and without consideration for solar activity variations. Recall that days of SSW (January 6) and solar activity (January 11) maxima do not coincide (vertical dashed lines). 

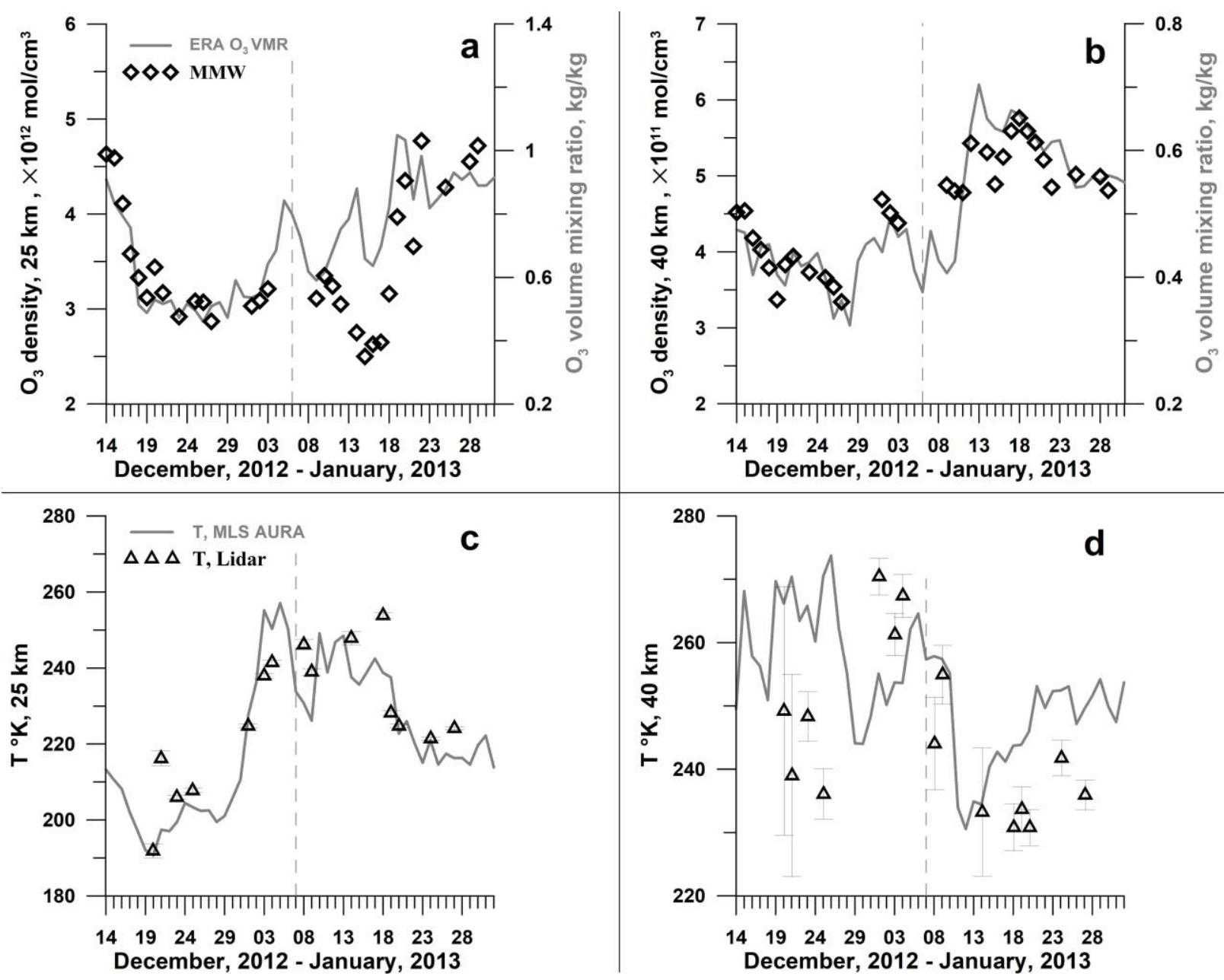

Figure 4. Ozone concentration variations in Tomsk at $25(a)$ and $40 \mathrm{~km}(b)$ according to the microwave observations (diamonds) in comparison with the behavior of the ozone volume mixing ratio from ERA-Interim reanalysis (gray curves). Stratospheric temperature variations at $25(c)$ and $40 \mathrm{~km}(d)$ obtained from lidar measurements are shown by triangles; and those from MLS Aura data, by gray curves

Solar activity makes a significant contribution to variations in ionospheric parameters - for all the three values there is a distinct response to the increase in solar activity from the beginning of January. We should take note of a delay in maxima of modeled $f_{\mathrm{o}} \mathrm{F} 2$, TEC, and $\mathrm{O} / \mathrm{N}_{2}$ with respect to solar activity maximum. Unlike the electron density (1-2 day delay after the $F 10.7$ peak), for $\mathrm{O} / \mathrm{N}_{2}$ the delay relative to $F 10.7$ peak is 4 days. Observations do not allow us to talk about the delay in variations of these parameters relative to solar activity because of their considerable day-to-day variability after the SSW maximum.

There are also ionospheric parameter variations unrelated to heliophysical conditions. From December 14 to the end of the month under quiet heliophysical conditions, daytime ionospheric electron density and TEC decreased. Values of $F 10.7$ decreased by less than $10 \%$ in this period; for $f_{\mathrm{o}} \mathrm{F} 2$, by $\sim 15 \%$; and midday TEC decreased by more than $40 \%$. Such a strong decrease in TEC cannot be fully explained by weak variations in solar activity.

In the period of interest there were also three periods of increased geomagnetic activity $\left(K_{\mathrm{p}} \geq 3\right)$ : December 16-18, January 20-21, and January 25-27. The $f_{\mathrm{o}} \mathrm{F} 2$ and TEC variations during these days (a noticeable decrease in December 17, January 20 and 25) are likely to be associated with increased geomagnetic activity. However, these geomagnetic disturbances were not strong enough to cause the above long-term and intensive variations in ionospheric parameters.

Note also that if, according to the model calculations, maximum $f_{0} \mathrm{~F} 2$ and TEC should have been detected on January 12-13, i.e. near the solar maximum, the experimental data do not show such behavior. Both in Tomsk and in Irkutsk, $f_{0} \mathrm{~F} 2$ and TEC peaked on January 7-8 and remained high until the end of January, not following the solar activity decrease. In this case, the TEC and $f_{\mathrm{o}} \mathrm{F} 2$ values before and after the SSW maximum differed more than twice. Similar variations in the peak electron density were observed in Norilsk during the SSW events, which occurred from 2006 to 2013 [Yasyukevich, 2018].

Next, we analyze $\mathrm{O} / \mathrm{N}_{2}$ variations from satellite measurements and model calculations. Variations in $\mathrm{O} / \mathrm{N}_{2}$ significantly affect the F2 layer electron density. Notice that the model results are obtained for $250 \mathrm{~km}$ height, whereas the GUVI data are column integrated $\mathrm{O} / \mathrm{N}_{2}$ ratio. The experimental and model $\mathrm{O} / \mathrm{N}_{2}$ ratios are therefore different. We, however, assume that their 

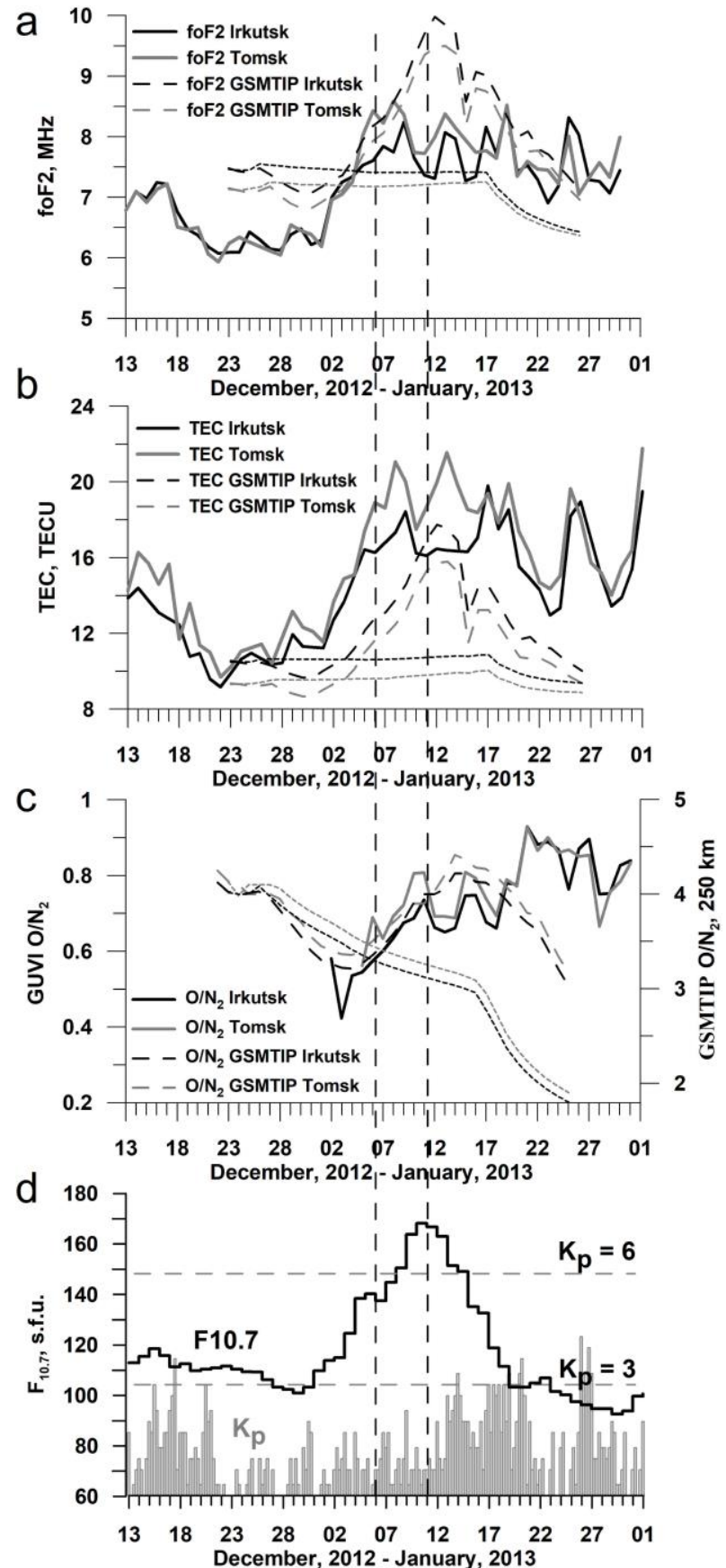

Figure 5. Variations in midday values of $f_{\mathrm{o}} \mathrm{F} 2(a)$; TEC (b); $\mathrm{O} / \mathrm{N}_{2}(c)$ (experimental data are shown by bold curves; model calculations with consideration for solar activity changes, by dashed lines, without consideration for them, by dotted lines); $F 10.7$ and $K_{\mathrm{p}}$ variations (d)

dynamics should be qualitatively the same. We can see that for $\mathrm{O} / \mathrm{N}_{2}$ there are variations similar to those recorded for the electron density. From early January, $\mathrm{O} / \mathrm{N}_{2}$ increased monotonically due to solar activity variations. Values of $\mathrm{O} / \mathrm{N}_{2}$, according to observations, remained elevated until the end of January, which is not related to solar activity changes. This conclusion follows from the discrepancy between time variations in the observations and model calculations. Note also that, as for the electron density and TEC, for $\mathrm{O} / \mathrm{N}_{2}$ there is a pronounced negative response to the weak geomagnetic disturbance of January $26\left(K_{\mathrm{p}} \leq 4\right)$.
Thus, the ionospheric effects of SSW over Tomsk and Irkutsk are:

1) a decrease in $f_{\mathrm{o}} \mathrm{F} 2$ and TEC during the warming development phase;

2) a long-term, for $\sim 20$ days after the SSW maximum, increase in $\mathrm{O} / \mathrm{N}_{2}, f_{\mathrm{o}} \mathrm{F} 2$, and TEC during the recovery phase of the stratospheric circulation.

These electron density variations are associated with the neutral composition variations, in particular with the $\mathrm{O} / \mathrm{N}_{2}$ variations. Available experimental data on the $\mathrm{O} / \mathrm{N}_{2}$ behavior during the period of interest confirm this assumption. Unfortunately, we were unable to assess the $\mathrm{O} / \mathrm{N}_{2}$ behavior in December because of the lack of satellite measurements at the latitudes under study for this period. Similar variations in the atomic oxygen density in the thermosphere during SSW are described in [Shepherd, Shepherd, 2011]; the authors have concluded that the observed effects are caused by SSW-related adiabatic vertical motions in the atmosphere.

An increase in the thermospheric temperature during SSW may also influence the ionospheric electron density. The model calculations [Klimenko et al., 2013] have shown that the temperature rise in the lower thermosphere during the SSW maximum leads to a decrease in $\mathrm{O} / \mathrm{N}_{2}$, which causes a decrease in the electron density at the F2-layer peak, by analogy with processes occurring during geomagnetic storms. After the warming maximum there may occur an equivalent of the after-storm effect [Klimenko et al., 2017, 2018b] when in the midlatitude ionosphere $\mathrm{O} / \mathrm{N}_{2}$ increases, as well as plasma may flow from the disturbed equatorial ionosphere where a significant increase in the electron density is detected after the SSW maximum [Goncharenko et al., 2013]. Positive disturbances of $\mathrm{O} / \mathrm{N}_{2}$ after stratospheric warmings have been previously discussed using four SSW as an example [Yasyukevich, 2018]. In this paper, we have examined in more detail the most complex of the four cases, for which it is proved that the positive disturbances in $\mathrm{O} / \mathrm{N}_{2}$ after January 13 are not associated with solar activity variations but are likely to be a manifestation of variations in the lower atmosphere parameters due to SSW.

And finally, we would like to point to a possible connection between variations in stratospheric ozone, thermosphere $\mathrm{O} / \mathrm{N}_{2}, f_{\mathrm{o}} \mathrm{F} 2$, and TEC. Values of all these parameters over Tomsk increase for a long time after the SSW maximum. A similar situation in the lowlatitude stratosphere and ionosphere was discussed in [Goncharenko et al., 2012 ] for the 2009 major SSW. It is important to note here that we do not assert that the stratospheric ozone through a certain process chain influences the thermospheric composition (which is also possible), but we merely point to their similar behavior at midlatitudes during the 2013 SSW. The relationship between the stratospheric ozone, thermospheric composition and the ionospheric electron density requires statistical studies using different experimental datasets and interpretation based on existing and developed numerical self-consistent models of the lower, middle, and upper atmosphere. 


\section{CONCLUSION}

This paper reports the results of observations of various parameters of the middle and upper atmosphere over Siberia in December 2012 - January 2013, during a major SSW event. We have demonstrated significant changes occurring in various atmospheric layers. The simulation results allowed us to separate the upper atmosphere response to SSW from the response to significant solar activity changes during the period of interest. To the upper atmosphere response to SSW we can assign a decrease in $f_{0} \mathrm{~F} 2$ and TEC during SSW development and a long-term increase in $\mathrm{O} / \mathrm{N}_{2}, f_{\mathrm{o}} \mathrm{F} 2$, and TEC after the SSW maximum. For the first time, we observed a relationship between the increases in the stratospheric ozone, thermospheric $\mathrm{O} / \mathrm{N}_{2}$, and ionospheric electron density at midlatitudes over a relatively long period of time (up to 20 days) after the SSW maximum.

We note that the approach used in this study is not without some shortcomings because GSM TIP ignores possible changes in the lower atmosphere due to solar activity increase. To interpret ionospheric disturbances during the period of interest more correctly, it is necessary to use a model describing the behavior of the parameters of the lower and upper atmosphere. In future, we plan to carry out such a study.

We express gratitude to the International GNSS Service for access to GNSS data used in this study; the European Centre for Medium-Range Weather Forecasts and Atmospheric Chemistry and Dynamics Laboratory/Goddard Space Flight Center for reanalysis meteorological data; Aerospace Corporation and Johns Hopkins University for satellite data GUVI/TIMED; NASA GES DISC service for Aura data; as well as the OMNIWeb Plus NASA/Goddard Space Flight Center service for the data on geomagnetic indices. Irkutsk ionosonde data were obtained using the equipment of Center for Common Use «Angara» [http://ckp-angara.iszf.irk.ru].

The study was supported by RFBR grant No. 1635-60018 (Yasyukevich A.S. - processing and analysis of satellite, reanalysis, and GPS/GLONASS data), No. 18-05-00594 (Klimenko M.V., Ratovsky K.G. processing, analysis, and interpretation of Irkutsk ionosonde data), and RSF grant No. 17-17-01060 (Klimenko V.V., Bessarab F.S., Korenkov Yu.N. model calculations and their analysis). We have used data processing methods developed within budgetary funding of Basic Research program II-16.

\section{REFERENCES}

Baldwin M.P., Dameris M., Shepherd T.G. How will the stratosphere affect climate change? Science. 2007, vol. 316 , pp. 1576-1577. DOI: 10.1126/science.1144303.

Bessarab F.S., Korenkov Yu.N., Klimenko M.V., Klimenko V.V., Karpov I.V., Ratovsky K.G., Chernigovskaya M.A. Modeling the effect of sudden stratospheric warming within the thermosphere-ionosphere system. J. At mos. Solar-Terr. Phys. 2012, vol. 90-91, pp. 77-85. DOI: 10.1016/j. jastp.2012.09.005.

Charlton A.J., Polvani L.M. A new look at stratospheric sudden warmings. Part I: climatology and modeling benchmarks. $J$. Climate. 2007, vol. 20, pp. 449-469. DOI: 10.1175/JCLI3996.1.

Chau J.L., Fejer B.G., Goncharenko L.P. Quiet variabil- ity of equatorial $\mathrm{E} \times \mathrm{B}$ drifts during a sudden stratospheric warming event. Geophys. Res. Lett. 2009, vol. 36, L05101. DOI: 10.1029/2008GL036785.

Chau J.L., Aponte N.A., Cabassa E., Sulzer M.P., Goncharenko L.P., Gonzalez S.A. Quiet time ionospheric variability over Arecibo during sudden stratospheric warming events. J. Geophys. Res. 2010, vol. 115, A00G06. DOI: 10.1029/2010JA015378.

Chau J.L., Goncharenko L.P., Fejer B.G., Liu H.L. Equatorial and low latitude ionospheric effects during sudden stratospheric warming events. Space Sci. Rev. 2012, vol. 168, pp. 385-417. DOI: 10.1007/s11214-011-9797-5.

Christensen A.B., Paxton L.J., Avery S., Craven J., Crowley G., Humm D.C., et al. Initial observations with the Global Ultraviolet Imager (GUVI) in the NASA TIMED satellite mission. J. Geophys. Res. 2003, vol. 108, iss. A12, CiteID 1451. DOI: 10.1029/2003JA009918.

Dee D.P., Uppala S.M., Simmons A.J., Berrisford P., Poli P., et al. The ERA-Interim reanalysis: configuration and performance of the data assimilation system. Q. J. R. Meteorol. Soc. 2011, vol. 137, pp. 553-597. DOI: 10.1002/qj.828.

Dow J.M., Neilan R.E., Rizos C. The International GNSS Service in a changing landscape of Global Navigation Satellite Systems. J. of Geodesy. 2009, vol. 83, pp. 191-198. DOI: $10.1007 / \mathrm{s} 001$ 90-008-0300-3.

Fuller-Rowell T., Wu F., Akmaev R., Fang T.-W., AraujoPradere E. A whole atmosphere model simulation of the impact of a sudden stratospheric warming on thermosphere dynamics and electrodynamics. J. Geophys. Res. 2010, vol. 115, A00G08. DOI: 10.1029/2010JA015524.

Hocke K., Lainer M., Schanz A. Composite analysis of a major sudden stratospheric warming. AnGeo Comm. 2015, vol. 33, pp. 783-788. DOI: 10.5194/angeocom-33-783-2015.

Goncharenko L., Zhang S.-R. Ionospheric signatures of sudden stratospheric warming: Ion temperature at middle latitude. Geophys. Res. Lett. 2008, vol. 35, L21103. DOI: 10.1029/ 2008GL035684.

Goncharenko L.P., Chau J.L., Liu H.L., Coster A.J. Unexpected connections between the stratosphere and ionosphere. Geophys. Res. Lett. 2010a, vol. 37, L10101. DOI: 10.1029/201 0GL043125.

Goncharenko L.P., Coster A.J., Chau J.L., Valladares C.E. Impact of sudden stratospheric warmings on equatorial ionization anomaly. J. Geophys. Res. 2010b, vol. 115 (A10), DOI: 10.1029/ 2010JA015400.

Goncharenko L.P., Coster A.J., Plumb R.A., Domeisen D.I.V. The potential role of stratospheric ozone in the stratosphereionosphere coupling during stratospheric warmings. Geophys. Res. Lett. 2012, vol. 39, L08101. DOI: 10.1029/20 12GL051261.

Goncharenko L.P., Chau J.L., Condor P., Coster A., Benkevitch L. Ionospheric effects of sudden stratospheric warming during moderate-to-high solar activity: Case study of January 2013. Geophys. Res. Lett. 2013, vol. 40, pp. 1-5. DOI: $10.1002 / \mathrm{grl} .50980$.

Klimenko M.V., Klimenko V.V., Koren'kov Y.N., Bessarab F.S., Karpov I.V., Ratovsky K.G., Chernigovskaya M.A. Modeling of response of the thermosphere-ionosphere system to sudden stratospheric warmings of years 2008 and 2009. Cosmic Res. 2013, vol. 51, no. 1, pp. 54-63. DOI: 10.1134/S0010 95251301005X.

Klimenko M.V., Klimenko. V.V., Bessarab F S., Korenkov Y.N., Liu. H., Goncharenko L.P., Tolstikov M.V. Study of the thermospheric and ionospheric response to the 2009 sudden stratospheric warming using TIME-GCM and GSM TIP models: First results. J. Geophys. Res.: Space Phys. 2015, vol. 120. DOI: $10.1002 / 2014 J A 020861$.

Klimenko M.V., Klimenko V.V., Zakharenkova I.E., Ratovsky K.G., Korenkova N.A., Yasyukevich Yu.V., Mylniko- 
va A.A., Cherniak Iu.V. Similarity and differences in morphology and mechanisms of the foF2 and TEC disturbances during the geomagnetic storms on 26-30 September 2011. Ann. Geophys. 2017, vol. 35, pp. 923-938. DOI: 10.5194/angeo-35-923-2017.

Klimenko M.V., Bessarab F.S., Sukhodolov T.V., Klimenko V.V., Koren'kov Yu.N., Zakharenkova I.E., Chirik N.V., Vasil'ev P.A., Kulyamin D.V., Shmidt Kh., Funke B., Rozanov E.V. Ionospheric Effects of the Sudden Stratospheric Warming in 2009: Results of Simulation with the First Version of the EAGLE Model. Russian Journal of Physical Chemistry B. 2018a, vol 12, no. 4, pp 760-770. DOI: 10.1134/S1990793 118040103.

Klimenko M.V., Klimenko V.V., Despirak I.V., Zakharenkova I.E., Kozelov B.V., Cherniakov S.M., Andreeva E.S., Tereshchenko E.D., Vesnin A.M., Korenkova N.A., Gomonov A.D., Vasiliev E.B., Ratovsky K.G. Disturbances of the thermosphere-ionosphere-plasmasphere system and auroral electrojet at $30^{\circ}$ E longitude during the St. Patrick's Day geomagnetic storm on 17-23 March 2015. J. Atmos. Solar-Terr. Phys. 2018b. DOI: 10.1016/j.jastp.2017.12.017.

Korenkov Yu.N., Klimenko V.V., Forster, M. Bessarab, F.S. Surotkin V.A. Calculated and observed ionospheric parameters for Magion-2 passage above EISCAT on July 31 1990. J. Geophys. Res. 1998, vol. 103(A7), pp. 14697-14710. DOI: $10.1029 / 98 J A 00210$.

Korenkov Y.N., Klimenko V.V., Klimenko M.V., Bessarab F.S., Korenkova N.A., Ratovsky K.G., Chernigovskaya M.A., Shcherbakov A.A., Sahai Y., Fagundes P.R., de Jesus R., de Abreu A.J., Condor P. The global thermospheric and ionospheric response to the 2008 minor sudden stratospheric warming event. J. Geophys. Res. 2012, vol. 117, A10309. DOI: 10.1029/2012JA018018.

Kulikov Yu.Yu., Krasil'nikov A.A., Ryskin V.G. Microwave Studies of the Structure of the Polar-Latitude Ozone Layer during Winter Anomalous Warming Events in the Stratosphere. Izvestiya. Atmospheric and Oceanic Physics. 2002, vol. 38, no. 2, pp. 158-166.

Kulikov Y.Y., Krasilnikov A.A., Ryskin V.G., Shanin V.N., Shchitov A.M. Ground-based microwave instrument for stratospheric ozone measurements: New design and some results of observations. Proc. 30 ${ }^{\text {th }}$ Annual Seminar "Physics of Auroral Phenomena". 2007, pp. 218-221.

Labitzke K. Temperature changes in the mesosphere and stratosphere connected with circulation changes in winter. $J$. Atmos. Sci. 1972, vol. 29, pp. 756-766. DOI: 10.1175/15200469(1972)029<0756:TCITMA>2.0.CO;2.

Labitzke K. Stratospheric-mesospheric midwinter disturbances: a summary of observed characteristics. J. Geophys. Res. 1981, vol. 86 (C10), pp. 9665-9678. DOI: 10.1029/JC086 iC10p09665.

Laskar F.I., Pallamraju D. Does sudden stratospheric warming induce meridional circulation in the mesospherethermosphere system? J. Geophys. Res.: Space Phys. 2014, vol. 119, pp. 10,133-10,143. DOI: 10.1002/2014JA020086.

Liu H.-L., Roble R.G. A study of a self-generated stratospheric sudden warming and its mesospheric-lower thermospheric impacts using the coupled TIME-GCM/CCM3. $J$. Geophys. Res. 2002, vol. 107 (D23), 4695. DOI: 10.1029/20 01JD001533.

Lukianova R., Kozlovsky A., Shalimov S., Ulich T., Lester M. Thermal and dynamical perturbations in the winter polar mesosphere-lower thermosphere region associated with sudden stratospheric warmings under conditions of low solar activity. J. Geophys. Res.: Space Phys. 2015, vol. 120. DOI: 10.1002/2015 JA021269.

Manney G.L., Lawrence Z.D., Santee M.L., Livesey N.J., Lambert A., Pitts M.C. Polar processing in a split vortex: Arctic ozone loss in early winter 2012/2013. Atmos. Chem. Phys. 2015, vol. 15, pp. 5381-5403. DOI: 10.5194/acp-15-5381-2015.

Marichev V.N., Matvienko G.G., Lisenko A.A., Bochkovsky D.A., Kulikov Yu.Yu., Krasilnikov A.A., Ryskin V.G., Demkin V.M. Microwave and optical observations of ozone and temperature of the middle atmosphere during stratospheric warming in the Western Siberia. Optika atmosfery $i$ okeana [Atmospheric and Oceanic Optics]. 2014, vol. 27, no. 01, pp. 46-52. (In Russian).

Matsuno T. A dynamical model of the stratospheric sudden warming. J. Atm. Sci. 1971, vol. 28, pp. 1479-1494.

Matvienko G.G., Banakh V.A., Bobrovnikov S.M., Burlakov V.D., Veretennikov V.V., Kaul B.V., Krekov G.M., Marichev V.N. Development of technologies of the atmosphere laser sounding. Optika atmosfery $i$ okeana [Atmospheric and Oceanic Optics]. 2009, vol. 22, no. 10, pp. 915-930. (In Russian).

Matvienko G.G., Kulikov Yu.Yu., Marichev V.N., Bochkovsky D.A., Krasilnikov A.A., Ryskin V.G. Study of the influence of the stratospheric warming in January 2013 on the vertical structure of ozone and temperature in the middle atmosphere over Tomsk using microwave and lidar diagnostics. ILRC 27 EPJ Web of Conferences. 2016, vol. 119, 24002. DOI: 10.1051/epjconf/2016119224002.

Medvedeva I., Medvedev A., Ratovsky K., Shcherbakov A., Tolstikov M. Comprehensive study of disturbances of the neutral atmosphere and ionosphere parameters over Eastern Siberia during the 2013 January major sudden stratospheric warming. Adv. Space Res. 2015, vol. 56, pp. 1877-1885. DOI: 10.1016/j.asr.2015.06.008.

Namgaladze A.A., Korenkov Yu.N., Klimenko V.V., Karpov I.V., Bessarab F.S., Surotkin V.A., Glushchenko T.A., Naumova N.M. Global model of the thermosphereionosphere-protonosphere system. Pure and Applied Geophys. 1988, vol. 127, no. 2/3, pp. 219-254. DOI: 10.1007/BF00879812.

Pancheva D., Mukhtarov P. Stratospheric warmings: The atmosphere - ionosphere coupling paradigm. J. Atmos. Solar-Terr. Phys. 2011, vol. 73, pp. 1697-1702. DOI: 10.1016/j. jastp.2011.03.006.

Pedatella N.M., Liu H.-L., Sassi F., Lei J., Chau J.L., Zhang X. Ionosphere variability during the 2009 SSW: Influence of the lunar semidiurnal tide and mechanisms producing electron density variability. J. Geophys. Res.: Space Phys. 2014, vol. 119, pp. 3828-3843. DOI: 10.1002/2014JA019849.

Pogoreltsev A.I., Savenkova E.N., Pertsev N.N. Sudden stratospheric warmings: the role of normal atmospheric modes. Geomagnetizm $i$ aeronomiya [Geomagnetism and Aeronomy]. 2014, vol. 54, no. 3, pp. 387-403. (In Russian). DOI: $10.7868 /$ S0016794014020163.

Polyakova A.S., Chernigovskaya M.A., Perevalova N.P. Ionospheric effects of sudden stratospheric warmings in Eastern Siberia region. J. Atmos. Solar-Terr. Phys. 2014, vol. 120, pp. 15-23. DOI: 10.1016/j.jastp.2014.08.011.

Schoeberl M.R. Stratospheric warmings: observations and theory. Rev. Geophys.: Space Phys. 1978, vol. 16 (4), pp. 521-538.

Scheiben D., Straub C., Hocke K., Forkman P., Kampfer N. Observations of middle atmospheric $\mathrm{H} 2 \mathrm{O}$ and $\mathrm{O} 3$ during the 2010 major sudden stratospheric warming by a network of microwave radiometers. Atmos. Chem. Phys. 2012, vol. 12, pp. 7753-7765. DOI: 10.5194/acp-12-7753-2012.

Shepherd M.G., Shepherd G.G. Stratospheric warming effects on thermospheric $\mathrm{O}(1 \mathrm{~S})$ dayglow dynamics. J. Geophys. Res. 2011, vol. 116, A11327. DOI: 10.1029/2011JA016762.

Shepherd M.G., Cho Y.-M., Shepherd G.G., Ward W., Drummond J.R. Mesospheric temperature and atomic oxygen 
response during the January 2009 major stratospheric warming. J. Geophys. Res. 2010, vol. 115, A07318, DOI: 10.1029/2009JA0 15172.

Shpynev B.G., Churilov S.M., Chernigovskaya M.A. Generation of waves by jet-stream instabilities in winter polar stratosphere/mesosphere. J. Atm. Solar-Terr. Phys. 2015a, vol. 136, Part B, pp. 201-215. DOI: 10.1016/j.jastp.2015.07.005.

Shpynev B.G., Kurkin V.I., Ratovsky K.G., Chernigovskaya M.A., Belinskaya A.Yu., Grigorieva S.A., Stepanov A.E., Bychkov V.V., Pancheva D., Mukhtarov P. High-midlatitude ionosphere response to major stratospheric warming. Earth, Planets and Space. 2015b, vol. 67:18. DOI: 10.1186/ s40623-015-0187-1.

Smyshlyaev S.P., Pogoreltsev A.I., Drobashevskaya E.A., Galin V.Y. Influence of wave activity on the composition of the polar stratosphere. Geomagnetism and Aeronomy. 2016, vol. 56, no. 1, pp. 95-109. DOI: 10.1134/S0016793215060146.

Solomonov S.V., Kropotkina E.P., Rozanov S.B., Ignat'ev A.N., Lukin A.N. Influence of strong sudden stratospheric warmings on ozone in the middle stratosphere according to millimeter wave observations. Geomagnetism and Aeronomy. 2017, vol. 57, no. 3, pp 361-368, DOI: 10.1134/S0016793217020141.

Strickland D.J., Meier R.R., Walterscheid R.L., Craven J.D., Christensen A.B., Paxton L.J., Morrison D., Crowley G. Quiettime seasonal behavior of the thermosphere seen in the far ultraviolet dayglow. J. Geophys. Res. 2004, vol. 109, A01302. DOI: 10.1029/2003JA010220.

Sun L., Robinson W.A. Downward influence of stratospheric final warming events in an idealized model. Geophys. Res. Lett. 2009, vol. 36, L03819. DOI: 10.1029/2008GL036624.

Tao M., Konopka P., Ploeger F., Grooß J.-U., Müller R., Volk C.M., Walker K.A., Riese M. Impact of the 2009 major sudden stratospheric warming on the composition of the stratosphere. Atmos. Chem. Phys. 2015, vol. 15, pp. 8695-8715. DOI: $10.5194 / \mathrm{acp}-15-8695-2015$.
Yasyukevich A.S. Variations in ionospheric peak electron density during sudden stratospheric warmings in the Arctic region. J. Geophys. Res.: Space Phys. 2018, vol. 123. DOI: 10.1002/2017JA024739.

Yasyukevich Yu.V., Mylnikova A.A., Polyakova A.S. Estimating the total electron content absolute value from the GPS/GLONASS data. Res. Phys. 2015, vol. 5, pp. 32-33. DOI: 10.1016/j.rinp.2014.12.006.

Yasyukevich A.S., Chernigovskaya M.A., Mylnikova A.A., Shpynev B.G., Khabituev D.S. Studying the seasonal pattern of ionospheric variability over Eastern Siberia and Far East region from GPS/GLONASS data. Sovremennye problem distantsionnogo zondirovaniya Zemli iz kosmosa [Current Problems in Remote Sensing of the Earth from Space]. 2017, vol. 14, no. 3, pp. 226-239. (In Russian). DOI: 10.21046/ 2070-7401-2017-144-249-262.

Yue X., Schreiner W.S., Lei J., Rocken C., Hunt D.C., Kuo Y.-H., Wan W. Global ionospheric response observed by COSMIC satellites during the January 2009 stratospheric sudden warming event. J. Geophys. Res. 2010, vol. 115, A00G09. DOI: 10.1029/2010JA015466.

URL: http://www.esrl.noaa.gov (accessed July 2, 2018).

URL: https://gmao.gsfc.nasa.gov/reanalysis/MERRA (accessed July 2, 2018). 2018).

URL: https://disc.gsfc.nasa.gov/datasets (accessed July 2,

URL: http://ckp-angara.iszf.irk.ru (accessed July 2, 2018).

Yasyukevich A.S., Klimenko M.V., Kulikov Yu.Yu., Klimenko V.V., Bessarab F.S., Korenkov Yu.N., Marichev V.N., Ratovsky K.G., Kolesnik S.A. Changes in the middle and upper atmosphere parameters during the January 2013 sudden stratospheric warming. SolarTerrestrial Physics. 2018. Vol. 4. Iss. 4. P. 48-58. DOI: 10.12737/stp44201807. 